\title{
Mapping spatiotemporal heterogeneity in tumour progression by integrating high-throughput imaging and omics analysis
}

\author{
Pooja Annasaheb Patkulkar ${ }^{1,{ }^{*}}$, Ayalur Raghu Subbalakshmi ${ }^{1, *}$, \\ Mohit Kumar Jolly ${ }^{1, \#}$, Sanhita Sinharay ${ }^{1, \#}$ \\ *These authors contributed equally. \\ \#Authors to whom correspondence should be addressed: \\ mkjolly@iisc.ac.in (MKJ), sanhitas@iisc.ac.in (SS)
}

\begin{abstract}
Intratumoral heterogeneity associates with more aggressive disease progression and worse patient outcomes. Understanding the reasons enabling the emergence of such heterogeneity remains incomplete, which restricts our ability to manage it from a therapeutic perspective. Technological advancements such as high-throughput molecular imaging, single-cell omics and spatial transcriptomics now allow recording the patterns of spatiotemporal heterogeneity in a longitudinal manner, thus offering insights into the multi-scale dynamics of its evolution. Here, we review latest technological trends and biological insights from molecular diagnostics as well as spatial transcriptomics, both of which have witnessed a burgeoning growth in recent past in terms of mapping heterogeneity within tumor cell types as well as stromal constitution. We also discuss ongoing challenges, indicating possible ways to integrate insights across these methods to have a systems-level spatiotemporal map of heterogeneity in each tumor, and a more systematic investigation of implications of heterogeneity for the patient outcomes.
\end{abstract}

\section{Keywords}

Spatial transcriptomics, Molecular imaging, single-cell RNA-seq, intratumoral heterogeneity 


\section{Introduction}

The intrinsic heterogeneity in cancer cells can be attributed to their dynamic evolution in response to various stresses they face. This heterogeneity can exist at many levels (genomic, metabolomic, transcriptomic, epigenomic, proteomic etc.) and has clinical implications as it hinders accurate diagnosis and effective treatment, thereby often associating with worse outcomes across cancers ${ }^{1-4}$. Thus, in a heterogeneous tumour mass, cancer cells exhibit distinctly different molecular signatures. Comprehensive molecular characterization of tumours through consortia such as The Cancer Genome Atlas (TCGA) Research Network, have revealed specific subtypes in multiple cancers ${ }^{5,6}$, but recent investigations at a single-cell level have revealed that most, if not all, tumours contain cells from multiple subtypes, although in different proportions ${ }^{7-9}$.

Tumour heterogeneity does not have a singular cause; it rather accumulates from multitude of factors such as genetic, transcriptomic, epigenetic and microenvironmental variations. Intertumoural heterogeneity, that refers to heterogeneity in the same cancer between different patients, mainly originates from genetic and somatic alterations between patients whereas intra-tumoural heterogeneity that refers to heterogeneity in tumour cells within the same patient originates mainly from dynamic variations in tumour cells/tumour microenvironment within the same tumour ${ }^{4}$. Indeed, this intratumoural heterogeneity, both spatial and temporal, provides an escape mechanism for cancer cells against various therapies, ultimately posing a severe hindrance to the efficacy of personalized and adaptive cancer therapies ${ }^{10}$. Given spatiotemporal variations in microenvironment, it is possible to have different resistance mechanisms in same tumour, depending on biopsied tumour location ${ }^{11}$. Thus, resistance to cancer therapies can be largely resolved by accurate analysis of spatial and temporal heterogeneity in tumours, and eventually aiming to eradicate the same through a better understanding of the underlying mechanisms.

Molecular diagnostics in all its advancement is unable to perfectly quantify intratumour variability within in vivo setting. For example, microarray analysis measures the transcriptome profiles in a large number of cells and provides an average measure of the bulk mass of cells/tissue, but it does not capture phenotypic and genotypic variance, thus limiting its use for precision medicine. Spatial transcriptomic methods developed recently offer a better resolution into mapping tumour heterogeneity, by classifying stromal signatures as well ${ }^{12}$. Tumour biopsies and random sampling methods are usually unable to capture the full extent of phenotypic or genetic variations. Hence, noninvasive methods of analyzing the whole tumour volume appears to be of clinical benefit in assessing intratumour heterogeneity and identifying cohorts of patients with poor prognosis and response to therapy ${ }^{13-15}$. Molecular imaging and particularly recent advances in image analysis methods have made appreciable advances towards exploring tumour heterogeneity in tumour progression and response to therapy. The significance of spatial structure in biological systems having long been established, the current clinical unmet need is to support the clinical implications of spatial heterogeneity through experimental results and development and integration of robust analytical, genomic and molecular imaging modalities to address this challenge; so as to control this heterogeneity and improve oncologic treatment outcomes.

The multiple complex interactions among diverse intra- and extra-cellular processes that leads to spatial and/or temporal heterogeneity enabling several cell phenotypes and various gene expression archetypes to emerge from the same lesion (genetic background) has been well documented in other reviews ${ }^{16-19}$. Here, we wanted to focus on examples of quantification of heterogeneity through two complementary recent technological advancements: a) how intratumour heterogeneity can be assessed from clinical radiology data to provide meaningful diagnostic and therapeutic interventions, and b) how spatial transcriptomics and single-cell data 
can be leveraged to better identify therapeutic vulnerabilities and treatment strategies. Correlating radiological heterogeneity features to spatial transcriptomics and/histopathology data can provide insights that may significantly improve therapeutic outcomes in patients.

\section{Molecular imaging of intratumour heterogeneity:}

The most commonly used clinical imaging modalities of computed tomography (CT), magnetic resonance Imaging (MRI), Positron emission tomography (PET)/ Single-photon emission computed tomography (SPECT) perform quantitative standard Region Of Interest (ROI) analysis that generates a mean parameter for all considered voxels and therefore does not necessarily estimate underlying spatial distribution. However, sophisticated image analysis methods have been developed now and can quantify spatial heterogeneity in these same imaging data obtained from CT, MRI, PET/SPECT images ${ }^{20}$. These methods can essentially add vital information about tumour heterogeneity over simple biomarkers such as tumour size and function and thus either quantify overall tumour spatial complexity or identify the tumour sub-regions that may drive disease transformation, progression, and drug resistance.

Histogram analysis: The histogram analysis is the most common and popular method of characterization of intratumour heterogeneity in imaging data. It measures image heterogeneity using parameters such as standard deviation, $\mathrm{n}^{\text {th }}$ centile, interquartile range, kurtosis and skewness as well as mean and median value ${ }^{21}$ and calculates the pixel intensity values and displays the distribution of pixels or "local spatial image density" in a grayscale mode.

In a study by Emblem et. al., the diagnostic accuracy for grading gliomas in patients were compared, using the histogram analysis of normalized cerebral blood volume maps (cBV) with the hot-spot method for dynamic contrast enhanced MRI in the patients. It was observed that the diagnostic accuracy and sensitivity of detection with histogram analysis for blood volume heterogeneity was much higher ( $90 \%)$ than for the hot-spot method $(55-76 \%)^{22}$.

In another study by Ma.et. al, the authors demonstrated the utility of the histogram method in delineating the heterogenous morphological features of the tumour vasculature for patients with histologically confirmed GBM, or lymphoma or solitary metastatic tumour. Patients underwent dynamic susceptibility contrast enhanced MRI (DSCE-MRI) along with conventional MRI, to probe the heterogeneity in tumour vasculature along with other changes in tumour anatomy. The semi quantitative histogram analysis, where 6 histogram parameters were analyzed from the normalized rCBV were able to accurately distinguish different enhancing and peri enhancing lesions for GBMs lymphoma and patients with solid metastatic lesions ${ }^{23}$.

Since glioblastoma pathology has well documented demonstrations of heterogeneous morphologic features of tumour capillaries with varying degrees of permeability within the same tumour, GBM images were mostly studied for identifying intratumour heterogeneity with such histogram analysis methods. In other dynamic contrast enhanced MRI studies (DCE -MRI) for monitoring tumour response to treatment in GBM patients, Peng et.al were able to quantify with modified full width at half-maximum (mFWHM) analysis of wash-in slope histograms, the changes in tumour heterogeneity on response to radiotherapy. Such tumour heterogeneity analysis demonstrated for brain tumours, showed that tumour progression could be measured from a function of the changes in tumour heterogeneity and not by tumour size alone ${ }^{24}$.

Texture analysis: Tumour heterogeneity as a prognostic factor, can help in grading tumours ${ }^{25,26}$. A limitation of histogram analysis is the inability to retain the spatial arrangement of the voxels. Other mathematical models such as texture analysis and fractal analysis, can account for 
intralesion heterogeneity and therefore has gained attraction in the field of medical image analysis in the last 10 years. Texture analysis applies mathematical models and statistical based methods to measure pixel-position, and relationship between neighboring pixels. For a particular lesion, the spatial information is extracted as gray-level intensity that ultimately generates spatial "texture features".

Texture analysis has been applied to CT and MRI images for improved diagnosis. In case of computed tomography (CT), unenhanced, contrast enhanced as well as derived images (such as perfusion $\mathrm{CT}$ ) can be analyzed for heterogeneity with texture analysis. In a study by Huang et al., using statistical based texture analysis, the authors correlated the 2D normalized autocovariance coefficient to interpixel correlations and were able to differentiate benign (84) from malignant (80) liver lesions in CT images ${ }^{27}$. Normally, CT involves the use of an iodinated contrast agent that generates contrast enhanced images for the tumour vs. normal tissue. lodinated contrast agents have issues of renal toxicity among others. This study could differentiate benign from malignant lesions based on the difference in spatial heterogeneity of the lesion without the need for any external contrast, thus signifying the potential of improved clinical diagnosis based on advanced image analysis methods that quantify tumour heterogeneity. Another study where CT texture analysis approach to account for spatial heterogeneity as a diagnostic biomarker was shown by $\mathrm{Ng}$. et al. and authors where texture features were compared between the largest cross-sectional area vs. the entire tumour and through measurements of entropy and uniformity the authors found that whole tumour rather than the chosen largest cross-sectional area was more representative of the tumour heterogeneity in a cohort of 55 colorectal tumour patients ${ }^{28}$. The potential of CT texture analysis in providing information regarding vascular heterogeneity that causes localized changes in blood flow leading to focal areas of hypoxia in the tumour, has been addressed as well ${ }^{29}$ and indeed vascular heterogeneity was shown to be well correlated to the CT texture analysis of entropy measures in patients of colorectal and primary NSCLC ${ }^{30}$. CT texture analysis was also able to quantify spatial heterogeneity and therefore differentiate renal lesions with excellent sensitivity and specificity ${ }^{31}$. As in CT, texture analysis of MRI data has also been applied to account for spatial heterogeneity, most significantly in breast, liver and brain tumour studies. For example, in breast cancer, apart from being able to distinguish between just benign and malignant lesions of breast cancer, texture analysis using co-occurrence matrix successfully differentiated invasive lobular carcinoma (ILC) from invasive ductal carcinoma (IDC), two common forms of invasive breast cancer ${ }^{32}$. Importantly, CT texture analysis established itself as prominent prognostic marker as well. Coarse texture analysis and uniformity in texture ratios served as significant predictors of overall survival in colorectal cancer patients (receiving cytotoxic therapy) independent of the tumour stage, or in renal cell cancer patients on antivascular therapy ${ }^{33,34}$. Apart from improved diagnosis and predicting survival outcomes in patients, texture analysis of CT images, has shown potential to assess response to therapy, although only a few studies have explored this so far. In fact, texture analysis proved to be a better predictor of treatment response in renal cell cancer metastases treated with tyrosine kinase inhibitors, compared to the current scale of treatment assessment, (response evaluation criteria in solid tumours, RECIST) ${ }^{35}$. In another study of $\sim 200$ women, Waugh et al. for the first-time used texture analysis to classify breast cancer subtypes based on pixel intensity distributions of CT images. Spatial heterogeneity was mapped from entropy-based features from co-occurrence matrix. This important classification could potentially improve monitoring and follow up of breast cancer patients on treatment regimens ${ }^{36}$.

Interestingly, only few studies in MRI have attempted to assess heterogeneity with treatment response $^{37}$. However, these studies have shown encouraging results that prove that texture changes in MRI can be a potential biomarker for treatment responses, such as texture changes observed in $T_{1}$ and $T_{2 w}$ MRI of non-Hodgkin lymphoma patients at staging, followed by post-first 
and fourth round of chemotherapy ${ }^{38}$. Compared to CT and MRI, the potential of texture analysis in PET imaging, especially for diagnosis, has not been widely explored ${ }^{39,40}$. One of the reasons for this could be the inherent low spatial resolution of PET images, large variability in implemented methodology and lack of technical details ${ }^{41}$. However, few attempts at texture analysis of PET images as a predictive marker of response to chemoradiation has shown that local (homogeneity, baseline entropy) and regional (size) texture parameters were better indicators than SUV measurements in differentiating responders vs. non responders ${ }^{42,43}$. Indeed, combination of image-derived texture features from both PET and CT or PET and MRI have predicted lung metastases in soft tissue sarcomas and characterized renal cell carcinoma ${ }^{44,45}$ (Fig 1).

\section{Fractal analysis:}

Fractal dimensions can be indicative of surface texture heterogeneity as well and therefore used in medical imaging where images reveal organs that have fluctuations in space and time and cannot be differentiated or characterized using one spatial or temporal scale ${ }^{46}$. The most useful fractal analysis model is the fractional Brownian motion model which quantifies the intensity surface of a medical image as the end result of a random walk ${ }^{47}$ and thereby correlate texture heterogeneity to fractal dimensions. Using fractal analysis, images of two textures for example can be distinguished based on the measure of lumpiness in them. As in texture-based methods, fractal analysis has been used also to distinguish as well as characterize benign and malignant lesions. For example, Kido et al. used fractal analysis of CT images and classified small lung lesions as benign or malignant, where benign hamartomas displayed a lower $2 \mathrm{D}$ fractal volume compared to malignant bronchogenic carcinomas, tuberculomas and pneumonias ${ }^{48}$. Other studies utilized 3D fractal dimensions from regular CT images and were able to differentiate adenocarcinomas from squamous cell carcinomas, and correlate greater heterogeneity in malignant nodes of colorectal cancer vs. benign nodes with an accuracy of $88 \%$. Fractal analysis was useful in patients with colorectal cancer where both fractal dimension and abundance from CT perfusion images were higher in the cancer vs. normal bowel ${ }^{49}$ and in repeatability measurements CT perfusion data of rectal adenocarcinoma patients, 2D and 3D fractal analysis of regional blood flow showed great correlation and good reproducibility ${ }^{50}$. Application of fractal geometry analysis to MRI analysis have been mostly applied to brain tumour MR images. For example, in a study by Di leva et al, patients with recurrent malignant brain tumour were imaged with MRI, particularly susceptibility weighted MR imaging to assess the change sin vasculature. The qualitative heterogeneity patterns from MR images, analyzed by fractal-based analysis methods was able to quantify the heterogeneity and provide the way to follow up brain tumours ${ }^{51}$. It was first shown by Rose et al, that spatial heterogeneity in dynamic contrast MRI (DCE MRI) maps could be quantified by fractal analysis and further be correlated to tumour grade ${ }^{52}$. In other studies, fractal analysis of voxel-based DCE-MRI data of breast cancer patients was able to deconvolute the texture at various spatial-frequency scales in a more accurate manner and therefore be marker for early prediction in breast cancer ${ }^{53}$.

Texture based analysis of radiology data has been also used for assisting in planning for therapy. Targeted radiation therapy is an area of cancer therapy where statistics-based model of texture analysis on co-registered PET/CT image in the clinic could identify abnormal nodes for radiotherapy by utilizing increased heterogeneity information in PET images and higher uniformity in CT. Tumour delineation which is essential for oncologists before radiation therapy was found to correlate better with automated texture-based segmentation as compared to the traditional thresholding SUV method. The anisotropic nature of voxels in commonly used radiology data from $\mathrm{CT}, \mathrm{MRI}$ or PET images makes it challenging for comparing the radiology images to histology data. When equated to histopathology and genomics data, the final in-space resolution of radiology data (200- $2000 \mu \mathrm{m}$ for preclinical and $500-5000 \mu \mathrm{m}$ for clinical) is orders of magnitude different from 
them therefore making it difficult for correlating spatial heterogeneity information obtained from pathology images to radiology data ${ }^{54,55}$.

Methods such as parcellation techniques which refer to grouping of "similar voxels" can isolate specific tumour subregions that might share similar tumour biology yet differ in their ability to resist therapy or promote progression. Parcellation methods of identifying tumour subregions with spatial heterogeneity can therefore be matched to histology of the same subregions for correlation of imaging and histology evidence of sublocal heterogeneity. The most common methods of parcellation techniques involve distinguishing based on a priori assumptions (threshold classification such as median apparent diffusion coefficients (ADC) in a diffusion-weighted MRI or binary classifiers, such as $\mathrm{K}_{\text {trans }}$ maps from perfusion MRI graphs) or multispectral analysis (combination of multiple imaging parameters such as Ktrans of DCE-MRI along with SUVmax of FDG PET). Results from the parcellation based spatial heterogeneity studies have supported the theory that analysis of tumour subregions may be more useful than accounting for average values from the entire tumour, when predicting tumour response to therapy or tumour progression ${ }^{56-59}$.

\section{New imaging methods focusing on spatial heterogeneity assessment:}

Metabolic activity in tumour cells is a well-established therapeutic target and a route for tumour evasion. Within the same tumour, different spatial distributions of metabolically distinct cell populations exist, at least partly driven by hypoxic gradients existing within a tumour ${ }^{60-63}$. This distribution can be quantified based on different drug responses displayed by them to differential cytotoxic drug treatments with the appropriate analysis method applied to the cell-level imaging data. A new analytical method was able to distinguish cell-level spatial heterogeneity in optical metabolic imaging data (obtained from two-photon microscopy experiments) and applying density based clustering and spatial principal component analysis (SPA) to relate the multivariate measurements of cell metabolism ${ }^{64,65}$ with spatial trends across models and treatments conditions $^{66}$. Briefly, the optical imaging data quantified the mean lifetimes $(\zeta \mathrm{m})$ of $\mathrm{NAD}(\mathrm{P}) \mathrm{H}$ and $F A D$, which are markers for metabolically different cell populations within the same tumour ${ }^{67-70}$ both in xenografts, and in 3D organoids. Spatial patterns of cellular drug response were correlated with drug diffusion to assess the influence of drug accessibility on cellular metabolic distributions. These methods could be translated to other optical metabolic imaging data acquired over an entire organoid volume or a superficial tumour volume to characterize 3D distributions of metabolism and drug response.

Optical microscopy methods although can provide rich contrast visualization of the tumour microenvironment, due to its limitation of low-depth penetration only a few microns of tissue depth can be assessed ${ }^{71}$. Optoacoustic/photoacoustic imaging, a relatively new technique that combines the advantage of rich optical contrast and high spatial resolution of ultrasound can image at larger penetration depth ( $\sim \mathrm{cm}$ range), and therefore has great potential for clinical translation ${ }^{72}$. Li et al. every recently developed a multispectral optoacoustic mesoscope (MSOM) for solid tumour imaging, an unique investigational tool for assessing spatial heterogeneity of tumour vasculature and tumour hypoxia at resolutions much higher $(\sim 50 \mu \mathrm{m})$ than what is offered by the current optoacoustic systems $(100-150 \mu \mathrm{m})$. Focal hypoxia is a prognostic biomarker of tumour progression in solid tumours therefore quantifying hypoxia maps in the overall tumour can provide valuable information for screening patients for personalized treatments ${ }^{73}$.

Yet another imaging modality that has gained momentum in the last few years for investigating the spatial distribution of variety of molecules in the complex biological system is mass spectrometry imaging (MSI). MSI attempts to provide the relative abundance of various molecules in a spatially 
resolved manner without the need for histological dissection or target-specific reagents as required in histopathological examinations of entire tumour tissue. Different ionization methods (MALDI, DESI, LEASI, SIMS) can be used resulting in ion density maps predicting relative intensity for each $\mathrm{m} / \mathrm{z}$ value detected at particular spatial localization ${ }^{74}$.

\section{Spatial transcriptomics in cancer}

Genomic and transcriptomic analysis have revealed multiple mutations including driver mutations of KRAS, CDKN2A, TP53, and SMAD4 ${ }^{75}$. Most of such characterization has been at a bulk level, with a few exceptions such as quantifying epithelial-mesenchymal heterogeneity at tumour interior vs. invasive edge ${ }^{76,77}$. Traditional transcriptomic methods result in loss of spatial information. To address this caveat, multiple spatial transcriptomic (ST) methods have been developed recently (Fig 2).

In a study involving engrafted human PDAC in ischemic hind limbs of nude mice, gene expression was observed to vary spatially depending on oxygenation of the microenvironment ${ }^{78}$. In the control group (normoxic conditions), the subgroups (SG) identified by spatial transcriptomics had diverse functions, such as enrichment of genes involved in proliferation in SG2, SG3, SG4 and SG11, but under hypoxic condition only SG6 showed properties of proliferation. Also, in the control group, SG10 showed enrichment of genes involved in response to hypoxia and angiogenesis, but in hypoxic group, genes related to angiogenesis and collagen organization was enriched in SG4. Both ST and IHC analysis revealed that LDHA (lactate dehydrogenase A) expression was found in the tumour boundary for both groups, but AKT was only upregulated in hypoxia. All subgroups under hypoxic condition showed a high metabolic rate, as revealed by GO and KEGG analysis. In another study of three PDAC human tumour samples, micro-array-based ST methods were integrated with single-cell RNA-seq to determine spatial patterns of gene expression by capturing the transcriptomes of a set of adjacent cells ${ }^{79}$. Multimodal intersection analysis was performed to annotate the precise cellular composition of distinct tissue regions. Interestingly, different cell types - ductal cells, macrophages, dendritic cells and cancer cells - had spatially enriched zones. Also, inflammatory fibroblasts and cancer cells that co-localized spatially exhibited stress-response profile, thus deciphering the spatial architecture seen in PDAC.

Besides PDAC, spatial and temporal intra-patient heterogeneity of metastatic tumours has been investigated in prostate adenocarcinoma tissue ${ }^{80}$. Here, unbiased clustering pinpointed a subset of samples with enrichment of small-cell neuroendocrine prostate cancer (SCNC) signature: low to absent expression of androgen receptor (AR) signaling, inactivation of TP53, PTEN and RB1 genes, elevated expression of ASCL1 and genes associated with small cell morphology, and increased levels of E2F1 and CDKN2A, reminiscent of observations in small cell lung cancer ${ }^{81}$. Among 14 patients who underwent therapy, only 3 of them evolved to a SCNC phenotype from adenocarcinoma phenotype, with varied levels of loss of AR signalling. Further, analysis of 176 primary and metastatic prostate tumours unravelled that both the phenotypes (adenocarcinoma, SCNC) could co-exist in a patient in distinct metastatic lesions, thereby indicating lineage plasticity 82. In another prostate cancer study, tissue samples from the patients who underwent radical prostatectomy were analysed using an artificial intelligence (Al) based method ${ }^{83}$. Differences between mp-MRI (multi-parametric MRI)-invisible and mp-MRI-visible prostate cancer tumours were visualized at a single-cell resolution through the annotated pipeline of segmentation, cell typing, modelling of tumour architecture and spatial interactions, and the employment of softwaregenerated masks. The visible mp-MRI tumours did not show specific boundaries between the stromal and glandular components, but invisible ones had a rounded glandular structure and had less closely spaced glands interspersed with stroma, thus bearing more similarity to normal 
prostate tissue ${ }^{83}$. Similarly, spatial transcriptomics on patient samples with adeno-carcinoma post radical prostatectomy revealed tissue-wide gene expression heterogeneity. Expression gradient of genes such as FOSB, AQP3 and NR4A1 was observed between tumour and stroma ${ }^{12}$. A novel deconvolution approach analysed transcriptomes of nearly 6750 tissue regions comprising stroma, normal and PIN glands, immune cells and cancer. This method showed accuracy in delineating the extent of cancer foci, similar to pathologist annotations, without directly looking at histological changes. Put together, spatial transcriptomic approaches have unravelled how different parts of a tumour may manifest the different stages of cancer progression, further indicating genetic and/or non-genetic components of cancer evolution at play, including those driven by different therapies. Further, spatial transcriptomics data can be used to develop spatially resolved metabolic network models of prostate tumour microenvironment ${ }^{84}$, thus identifying malignant cell-specific metabolic vulnerabilities targetable by small molecule compounds. For instance, based on the identification of spatial segregation of regions showing enrichment in fatty acid synthesis and desaturation, it was predicted that inhibiting the fatty acid desaturase SCD1 may selectively kill cancer cells. Thus, spatial transcriptomic data can also help pinpoint selective drug targets for specific cancer types. In addition to spatial transcriptomics, digital spatial profiling (DSP) can decode the underlying heterogeneity patterns in a tumour. DSP quantifies the abundance of both RNAs and proteins in spatially distinct regions using multiplexing, which is counting the uniquely indexed oligonucleotides to specific targets of interest in a fixed tissue ${ }^{85}$. These oligonucleotides can be attached to antibodies or RNA probes though a linker that is photocleavable; that is light projecting onto the tissue sample can release the photocleavable oligonucleotides in each spatial region. These light patterns can be manipulated to help profile distinct regions or cell type in a tumour or its microenvironment ${ }^{86}$. In a study using DSP to study samples obtained from 27 patients who died of metastatic castration resistant prostate cancer ${ }^{87}, 141$ regions of interest from 53 metastases (from diverse anatomic sites of tumour dissemination) were analysed. Six phenotypes of metastatic prostate cancer were identified, based on expression levels of genes associated with androgen receptor $(A R)$ and a small cell neuroendocrine (NE) phenotype: $A R+/ N E-, A R^{\text {low }} / N E-$, $A R-/ N E-, A R-/ N E^{\text {low }}, A R+/ N E+$, and $A R-/ N E+$. The DSP measurements of AR and NE activity scores - when averaged across regions of interest for a given sample - correlated well with bulk RNA-seq measurements done on corresponding frozen tumour tissue; suggesting a high level of intra-patient homogeneity. Majority of metastases were also devoid of significant inflammatory infiltrates, as they expressed at high levels B7-H3 (CD276), an immune checkpoint protein similar to PD-L1 (CD274) ${ }^{88}$. Thus, DSP can accurately classify tumour phenotype, assess heterogeneity in tumours and stromal components, and identifying aspects of tumour biology involving the immunological composition of metastases.

Beyond PDAC and prostate cancer, spatial transcriptomics has also been applied to breast cancer. Spatial mapping of samples from eight patients undergoing mastectomy revealed heterogeneity between sites based on their proximity to the tumour ${ }^{89}$. High copy number aberrations (CNAs) were identified at the morphologically normal epithelium sites closer to the tumour, but this variation was unable to explain diversity in corresponding gene expression profiles or mRNA abundance. Spectral co-clustering was used to identify bi-clusters, i.e. co-expressed sets of genes that are commonly upregulated (or downregulated) in certain samples closer to the tumour than those that are further away. This comprehensive spatial CNA and mRNA characterization of morphologically normal epithelium from primary tumours of patients representing different molecular subtypes suggested that Wnt signaling may be one of the first ones to change in breast cancer progression. In another spatial transcriptomic analysis of micro-dissected tissues from triple-negative breast cancer (TNBC) cell line MDA-MB-231 xenograft model, three cell-type clusters in primary tumour and axillary lymph node metastasis were revealed ${ }^{90}$. Two of these clusters were identified to be stem cell-like (CD44/MYC-high, HMGA1-high). scRNA-seq analysis on TNBC patient samples two 
cancer stem cell-like populations were detected similar to that observed in the xenograft model, highlighting potential common principles of heterogeneity in tumours. Given the complementary information available through spatial transcriptomics/digital profiling and scRNA-seq/ proteomics, methods integrating insights from these can be a powerful tool for potentially categorizing patients into different therapeutic regimes, depending on archetypes observed in a given tumour sample.

\section{Computational tools for spatial transcriptomics data analysis}

Many computational tools are being developed to integrate scRNA-seq and spatial transcriptomics. One such tool is SPOTlight ${ }^{91}$; it uses Nonnegative matrix factorization (NMF) to obtain cell-type specific topic profiles. Its performance was tested by using synthetic mixtures comprising of 2-8 cells from the peripheral blood mononuclear cell (PBMC) scRNA-seq datasets. When tested on these synthetic mixtures, it showed sensitivity of 0.911 , an accuracy of 0.78 , and Median Jensen Shannon Divergence (JSD) values of 0.160 , thus indicating high accuracy of estimated cell type proportions. It was also able to detect in a sensitive manner different cell types and other subtle cell states at their expected spatial locations, and predict accurately despite shallower sequencing. Another computational tool that identifies statistically significant spatial gene expression trends is Trendsceek ${ }^{92}$. It ranks and assesses the significance of spatial trends seen for each gene, thus identifying the set of genes for which dependencies exist between spatial distribution of cells and corresponding gene expression in those cells. It uses an approach where the spatial location of cell is given by an assigned point, and expression levels are captured by mark on each point. represent the spatial location of cells and mark on each point represents the expression levels. It was used to probe gene expression patterns from mouse olfactory bulb and breast tumour sections. Thus, this nonparametric method incorporates both spatial and expression-level information for a gene, thereby overcoming limitations of approaches using only one-dimensional information - pseudospace ${ }^{93}$ or pseudotime ${ }^{94,95}$. Several genes implicated in breast cancer were found to have crucial spatial patterns, such as the transcription factor KLF6 and the transmembrane protein PMEPA1.

Besides the above mentioned tools, a method designed for digital analysis of pathology wholeslide images identified the molecular traits, and showed a significantly statistical connection between survival and heterogeneity ${ }^{96}$. Methods using deep learning algorithm (ST-net) that combine spatial transcriptomics and histology images to capture high-resolution expression heterogeneity have also been recently developed ${ }^{97}$. ST-Net was trained on a spatial transcriptomic data from 68 breast tissue sections taken from 23 patients, and could predict the expression of 102 genes that correlated well with experimental measurements too. It takes a $224 \times 224$-pixel patch of the histopathology image corresponding to approximately $150 \times 150 \mu \mathrm{m}^{2}$ and predicts the expression of 250 specific genes. It was trained iteratively using leave-one-out analysis, i.e. taking 22 patients. Thus, its performance is affected by experimental noise in spatial transcriptomics data as well as the limited sequencing depth. For independent validation of this method, breast cancer samples from the 10x Genomics Spatial Gene Expression dataset were used. Corresponding transcriptomic dataset included measurements for 234 of the 250 genes that ST-Net was trained to predict. Out of the 234 genes available, the predicted expression of 207 of them were positively correlated with that seen in experimental data. Next, when applied to breast cancer samples in TCGA, ST-Net was used to scan H\&E images of 1,550 samples from 1,093 patients without any re-training. Because TCGA only has bulk RNA-seq data, a pseudo-bulk expression profile for each sample was derived from ST-Net predictions. For 177 out of 250 genes whose expression ST-Net could spatially resolve and predict, the correlation with experimental measurements was positive. Further, the inferred expression levels could help distinguish histological subtypes in breast cancer infiltrating ductal adenocarcinoma and infiltrating lobular carcinoma. Finally, ST-Net could also 
predict the top five genes that showed the highest variation in intra-tumour expression - GNAS, FASN, AEBP1, SPARC and BGN. Given that heterogeneity, instead of mean expression levels, itself can be a marker of aggressiveness in breast cancer too ${ }^{98}$, the framework proposed by STNet can be helpful in identifying patients with worse prognosis across multiple cancer types.

\section{Integrating single-cell measurements with spatial transcriptomics}

Single-cell high-throughput measurements at genomic, epigenetic, metabolomic, proteomic and chromatin levels are becoming more popular by the day ${ }^{99-101}$, but they often compromise on spatial and temporal information due to the tissue dissociation step. To overcome this limitation, methods such as fluorescent in situ sequencing (FISSEQ) ${ }^{102}$ have been developed to show in vivo messenger RNA localization within cells. But scaling in situ to perform whole genome sequencing is not easy. Thus, besides array-based approaches such as high-density spatial transcriptomics (HDST), a few methods can now obtain spatial information through approaches such as computational inference, gentle tissue dissociation and physical separation by laser microdissection $^{103,104}$.

One of the earlier technologies that allowed visualizing over 100 transcripts per sample with single cell resolution is single-molecule fluorescent in-situ hybridization (smFISH) ${ }^{105}$. It provided absolute quantification of copy number and localization of RNA molecules, and can detect low copy number transcripts as well. Earlier, it was limited by the number of available fluorescent channels, but multiplexing has now enabled using a larger number of targets $\left(=F^{\wedge} n ; F=\right.$ no. of fluorophores, $n=n o$. of hybridization cycles). This approach is called temporal barcoding (also called as sequential FISH or seqFISH) and can visualize $10,000+$ genes within a single cell by using specific barcodes ${ }^{106}$. While both FISSEQ and seqFISH are capable of measuring the expression of various genes while retaining single-cell resolution in a given field of view, they often have long acquisition times and thus assaying whole transcriptomes of single cells over large areas of interest are yet impractical. To overcome these limitations, "sci-Space" was developed to provide single-cell resolution, along with determining the spatial information on a larger scale ${ }^{107}$, thus offering advantage over spatial transcriptomics where each spot can still include RNA from multiple cells. It labels nuclei using unmodified DNA oligos before single-cell RNA sequencing with specific combinatorial indexing (sci-RNA-seq). This method was used to profile 14 sagittal sections derived from two embryonic day 14 (E14.0) mouse embryos (C57BL/6N), and led to approximately 120,000 spatially resolved single-cell transcriptomes. Albeit large, this number still accounts for only $2.2 \%$ nuclei present overall. Thus, this data was integrated with non-spatial sci-RNA-seq mouse organogenesis cell atlas dataset spanning adjacent time-points - E9.5 to E13.5 and cells from a developing mouse brain atlas spanning E13.5 to E14.5, thereby endorsing the ability of sci-RNA-seq in generating spatially resolved single-cell atlases of mammalian development. How this technique is applied to investigate the dynamics of tumour progression at a single-cell level remains to be demonstrated. A similar method that integrates histological staining and spatially resolved RNA-seq data has been developed to study mammalian tissue ${ }^{108}$. While it can be applied to most high-quality fresh-frozen tissue types, the spatial resolution is listed currently to $100 \mu \mathrm{m}$. Thus, it can be potentially used for identifying heterogeneity patterns in smaller regions of interest, thus limiting the number of cells that can be investigated at a time. Another workflow that can be applied for tumour samples is $X Y Z e q$ that encodes spatial metadata at $500 \mu \mathrm{m}$ resolution into scRNA seq libraries ${ }^{109}$. This method could assign transcriptomes to single cells in case of mixed-species experiment consisting of human [human embryonic kidney (HEK293T)] and mouse (NIH 3T3) cell mixtures. Mouse tumour models were profiled using XYZeq to capture the spatially barcoded transcriptomes from tens of thousands of cells, which led to identifying a cell migration-associated transcriptomic program in tumour-associated mesenchymal stem cells (MSCs). Thus, this method could map transcriptome 
and spatial localization of individual cells in situ, and can capture both spatially variable patterns of gene expression which is a function of cellular composition, as well as heterogeneity within a cell type depending on the spatial coordinates. Given that XYZeq can be adapted to many z-layers, it could potentially facilitate a three-dimensional map of heterogeneity within a tumour too. Together, these methods could enable a better understanding of how microenvironment shapes cell identity.

\section{Conclusion}

At present, molecular imaging analysis using texture and fractal dimensions have displayed their ability to account for spatial heterogeneity in radiological images of the entire tumour, however the reproducibility of these studies especially in larger cohorts need to be established for applying in the clinical scenario. More importantly, integrating spatially corrected imaging data with genomics and transcriptomics data and pathology biomarkers can bypass the caveats of heterogeneity related drug resistance in tumour and poor tumour prognosis. Also, emphasis should be given to imaging studies in preclinical animal models that take into account the spatial heterogeneity of the tumour environment as observed in humans. Various recent technological advancements have enabled mapping the spatiotemporal heterogeneity in tumours at varying degrees of resolution. Such deluge of information has also triggered the development of potent computational methods that can process such high-dimensional data into biologically meaningful insights; for instance, association of different localization patterns of tumour and/or stromal cell types in a tumour with patient outcomes. Future steps should integrate these advancements at technological and/or conceptual levels, with the goal of achieving a predictive systems-level multi-scale understanding of dynamic tumour microenvironment and its implication in terms of patient prognosis and outcome. This understanding can empower more targeted therapeutic interventions as well as a longitudinal monitoring of variability within patient response to therapy.

\section{Author contributions}

MKJ and SS supervised and conceived work and revised and edited the manuscript drafts, PAP and ARS conducted literature review and wrote the first draft of the manuscript.

\section{Funding}

MKJ acknowledges support by Ramanujan Fellowship awarded by Science and Engineering Research Board (SERB), Department of Science and Technology (DST), Government of India (SB/S2/RJN-049/2018).

\section{Conflict of Interest}

The authors declare no conflict of interest 


\section{References}

(1) Kim, J.; DeBerardinis, R. J. Mechanisms and Implications of Metabolic Heterogeneity in Cancer. Cell metabolism 2019, 30 (3), 434-446. https://doi.org/10.1016/J.CMET.2019.08.013.

(2) Chen, F.; Ding, K.; Priedigkeit, N.; Elangovan, A.; Levine, K. M.; Carleton, N.; Savariau, L.; Atkinson, J. M.; Oesterreich, S.; Lee, A. v. Single-Cell Transcriptomic Heterogeneity in Invasive Ductal and Lobular Breast Cancer Cells. Cancer research 2021, 81 (2), 268281. https://doi.org/10.1158/0008-5472.CAN-20-0696.

(3) Ramón y Cajal, S.; Sesé, M.; Capdevila, C.; Aasen, T.; de Mattos-Arruda, L.; Diaz-Cano, S. J.; Hernández-Losa, J.; Castellví, J. Clinical Implications of Intratumor Heterogeneity: Challenges and Opportunities. Journal of Molecular Medicine (Berlin, Germany) 2020, 98 (2), 161. https://doi.org/10.1007/S00109-020-01874-2.

(4) Grzywa, T. M.; Paskal, W.; Włodarski, P. K. Intratumor and Intertumor Heterogeneity in Melanoma. Translational Oncology 2017, 10 (6), 956-975. https://doi.org/10.1016/J.TRANON.2017.09.007.

(5) Bass, A. J.; Thorsson, V.; Shmulevich, I.; Reynolds, S. M.; Miller, M.; Bernard, B.; Hinoue, T.; Laird, P. W.; Curtis, C.; Shen, H.; Weisenberger, D. J.; Schultz, N.; Shen, R.; Weinhold, N.; Kelsen, D. P.; Bowlby, R.; Chu, A.; Kasaian, K.; Mungall, A. J.; Robertson, A. G.; Sipahimalani, P.; Cherniack, A. D.; Getz, G.; Liu, Y.; Noble, M. S.; Pedamallu, C.; Sougnez, C.; Taylor-Weiner, A.; Akbani, R.; Lee, J. S.; Liu, W.; Mills, G. B.; Yang, D.; Zhang, W.; Pantazi, A.; Parfenov, M.; Gulley, M.; Piazuelo, M. B.; Schneider, B. G.; Kim, J.; Boussioutas, A.; Sheth, M.; Demchok, J. A.; Rabkin, C. S.; Willis, J. E.; Ng, S.; Garman, K.; Beer, D. G.; Pennathur, A.; Raphael, B. J.; Wu, H. T.; Odze, R.; Kim, H. K.; Bowen, J.; Leraas, K. M.; Lichtenberg, T. M.; Weaver, S.; McLellan, M.; Wiznerowicz, M.; Sakai, R.; Lawrence, M. S.; Cibulskis, K.; Lichtenstein, L.; Fisher, S.; Gabriel, S. B.; Lander, E. S.; Ding, L.; Niu, B.; Ally, A.; Balasundaram, M.; Birol, I.; Brooks, D.; Butterfield, Y. S. N.; Carlsen, R.; Chu, J.; Chuah, E.; Chun, H. J. E.; Clarke, A.; Dhalla, N.; Guin, R.; Holt, R. A.; Jones, S. J. M.; Lee, D.; Li, H. A.; Lim, E.; Ma, Y.; Marra, M. A.; Mayo, M.; Moore, R. A.; Mungall, K. L.; Nip, K. M.; Schein, J. E.; Tam, A.; Thiessen, N.; Beroukhim, R.; Carter, S. L.; Cho, J.; DiCara, D.; Frazer, S.; Gehlenborg, N.; Heiman, D. I.; Jung, J.; Kim, J.; Lin, P.; Meyerson, M.; Ojesina, A. I.; Pedamallu, C. S.; Saksena, G.; Schumacher, S. E.; Stojanov, P.; Tabak, B.; Voet, D.; Rosenberg, M.; Zack, T. I.; Zhang, H.; Zou, L.; Protopopov, A.; Santoso, N.; Lee, S.; Zhang, J.; Mahadeshwar, H. S.; Tang, J.; Ren, X.; Seth, S.; Yang, L.; Xu, A. W.; Song, X.; Xi, R.; Bristow, C. A.; Hadjipanayis, A.; Seidman, J.; Chin, L.; Park, P. J.; Kucherlapati, R.; Ling, S.; Rao, A.; Weinstein, J. N.; Kim, S. B.; Lu, Y.; Bootwalla, M. S.; Lai, P. H.; Triche, T.; van den Berg, D. J.; Baylin, S. B.; Herman, J. G.; Murray, B. A.; Askoy, B. A.; Ciriello, G.; Dresdner, G.; Gao, J.; Gross, B.; Jacobsen, A.; Lee, W.; Ramirez, R.; Sander, C.; Senbabaoglu, Y.; Sinha, R.; Sumer, S. O.; Sun, Y.; Iype, L.; Kramer, R. W.; Kreisberg, R.; Rovira, H.; Tasman, N.; Haussler, D.; Stuart, J. M.; Verhaak, R. G. W.; Leiserson, M. D. M.; Taylor, B. S.; Black, A. D.; Carney, J. A.; Gastier-Foster, J. M.; Helsel, C.; McAllister, C.; Ramirez, N. C.; Tabler, T. R.; Wise, L.; Zmuda, E.; Penny, R.; Crain, D.; Gardner, J.; Lau, K.; Curely, E.; Mallery, D.; Morris, S.; Paulauskis, J.; Shelton, T.; Shelton, C.; Sherman, M.; Benz, C.; Lee, J. H.; Fedosenko, K.; Manikhas, G.; Potapova, O.; Voronina, O.; Belyaev, D.; Dolzhansky, O.; Rathmell, W. K.; Brzezinski, J.; Ibbs, M.; Korski, K.; Kycler, W.; Łaźniak, R.; Leporowska, E.; Mackiewicz, A.; Murawa, D.; Murawa, P.; Spychała, A.; Suchorska, W. M.; Tatka, H.; Teresiak, M.; Abdel-Misih, R.; Bennett, J.; Brown, J.; lacocca, M.; Rabeno, B.; Kwon, S. 
Y.; Kemkes, A.; Curley, E.; Alexopoulou, I.; Engel, J.; Bartlett, J.; Albert, M.; Park, D. Y.; Dhir, R.; Luketich, J.; Landreneau, R.; Janjigian, Y. Y.; Cho, E.; Ladanyi, M.; Tang, L.; McCall, S. J.; Park, Y. S.; Cheong, J. H.; Ajani, J.; Camargo, M. C.; Alonso, S.; Ayala, B.; Jensen, M. A.; Pihl, T.; Raman, R.; Walton, J.; Wan, Y.; Eley, G.; Shaw, K. R. M.; Tarnuzzer, R.; Wang, Z.; Yang, L.; Zenklusen, J. C.; Davidsen, T.; Hutter, C. M.; Sofia, H. J.; Burton, R.; Chudamani, S.; Liu, J. Comprehensive Molecular Characterization of Gastric Adenocarcinoma. Nature 2014 513:7517 2014, 513 (7517), 202-209. https://doi.org/10.1038/nature13480.

(6) Muzny, D. M.; Bainbridge, M. N.; Chang, K.; Dinh, H. H.; Drummond, J. A.; Fowler, G.; Kovar, C. L.; Lewis, L. R.; Morgan, M. B.; Newsham, I. F.; Reid, J. G.; Santibanez, J.; Shinbrot, E.; Trevino, L. R.; Wu, Y. Q.; Wang, M.; Gunaratne, P.; Donehower, L. A.; Creighton, C. J.; Wheeler, D. A.; Gibbs, R. A.; Lawrence, M. S.; Voet, D.; Jing, R.; Cibulskis, K.; Sivachenko, A.; Stojanov, P.; McKenna, A.; Lander, E. S.; Gabriel, S.; Ding, L.; Fulton, R. S.; Koboldt, D. C.; Wylie, T.; Walker, J.; Dooling, D. J.; Fulton, L.; Delehaunty, K. D.; Fronick, C. C.; Demeter, R.; Mardis, E. R.; Wilson, R. K.; Chu, A.; Chun, H. J. E.; Mungall, A. J.; Pleasance, E.; Gordon Robertson, A.; Stoll, D.; Balasundaram, M.; Birol, I.; Butterfield, Y. S. N.; Chuah, E.; Coope, R. J. N.; Dhalla, N.; Guin, R.; Hirst, C.; Hirst, M.; Holt, R. A.; Lee, D.; Li, H. I.; Mayo, M.; Moore, R. A.; Schein, J. E.; Slobodan, J. R.; Tam, A.; Thiessen, N.; Varhol, R.; Zeng, T.; Zhao, Y.; Jones, S. J. M.; Marra, M. A.; Bass, A. J.; Ramos, A. H.; Saksena, G.; Cherniack, A. D.; Schumacher, S. E.; Tabak, B.; Carter, S. L.; Pho, N. H.; Nguyen, H.; Onofrio, R. C.; Crenshaw, A.; Ardlie, K.; Beroukhim, R.; Winckler, W.; Meyerson, M.; Protopopov, A.; Hadjipanayis, A.; Lee, E.; Xi, R.; Yang, L.; Ren, X.; Sathiamoorthy, N.; Chen, P. C.; Haseley, P.; Xiao, Y.; Lee, S.; Seidman, J.; Chin, L.; Park, P. J.; Kucherlapati, R.; Todd Auman, J.; Hoadley, K. A.; Du, Y.; Wilkerson, M. D.; Shi, Y.; Liquori, C.; Meng, S.; Li, L.; Turman, Y. J.; Topal, M. D.; Tan, D.; Waring, S.; Buda, E.; Walsh, J.; Jones, C. D.; Mieczkowski, P. A.; Singh, D.; Wu, J.; Gulabani, A.; Dolina, P.; Bodenheimer, T.; Hoyle, A. P.; Simons, J. v.; Soloway, M.; Mose, L. E.; Jefferys, S. R.; Balu, S.; O’Connor, B. D.; Prins, J. F.; Chiang, D. Y.; Neil Hayes, D.; Perou, C. M.; Hinoue, T.; Weisenberger, D. J.; Maglinte, D. T.; Pan, F.; Berman, B. P.; van den Berg, D. J.; Shen, H.; Triche, T.; Baylin, S. B.; Laird, P. W.; Getz, G.; Noble, M.; Voat, D.; Gehlenborg, N.; Dicara, D.; Zhang, J.; Zhang, H.; Wu, C. J.; Liu, S. Y.; Shukla, S.; Zhou, L.; Lin, P.; Park, R. W.; Nazaire, M. D.; Robinson, J.; Thorvaldsdottir, H.; Mesirov, J.; Thorsson, V.; Reynolds, S. M.; Bernard, B.; Kreisberg, R.; Lin, J.; Iype, L.; Bressler, R.; Erkkilä, T.; Gundapuneni, M.; Liu, Y.; Norberg, A.; Robinson, T.; Yang, D.; Zhang, W.; Shmulevich, I.; de Ronde, J. J.; Schultz, N.; Cerami, E.; Ciriello, G.; Goldberg, A. P.; Gross, B.; Jacobsen, A.; Gao, J.; Kaczkowski, B.; Sinha, R.; Arman Aksoy, B.; Antipin, Y.; Reva, B.; Shen, R.; Taylor, B. S.; Ladanyi, M.; Sander, C.; Akbani, R.; Zhang, N.; Broom, B. M.; Casasent, T.; Unruh, A.; Wakefield, C.; Hamilton, S. R.; Craig Cason, R.; Baggerly, K. A.; Weinstein, J. N.; Haussler, D.; Benz, C. C.; Stuart, J. M.; Benz, S. C.; Zachary Sanborn, J.; Vaske, C. J.; Zhu, J.; Szeto, C.; Scott, G. K.; Yau, C.; Ng, S.; Goldstein, T.; Ellrott, K.; Collisson, E.; Cozen, A. E.; Zerbino, D.; Wilks, C.; Craft, B.; Spellman, P.; Penny, R.; Shelton, T.; Hatfield, M.; Morris, S.; Yena, P.; Shelton, C.; Sherman, M.; Paulauskis, J.; Gastier-Foster, J. M.; Bowen, J.; Ramirez, N. C.; Black, A.; Pyatt, R.; Wise, L.; White, P.; Bertagnolli, M.; Brown, J.; Chan, T. A.; Chu, G. C.; Czerwinski, C.; Denstman, F.; Dhir, R.; Dörner, A.; Fuchs, C. S.; Guillem, J. G.; lacocca, M.; Juhl, H.; Kaufman, A.; lii, B. K.; van Le, X.; Mariano, M. C.; Medina, E. N.; Meyers, M.; Nash, G. M.; Paty, P. B.; Petrelli, N.; Rabeno, B.; Richards, W. G.; Solit, 
D.; Swanson, P.; Temple, L.; Tepper, J. E.; Thorp, R.; Vakiani, E.; Weiser, M. R.; Willis, J. E.; Witkin, G.; Zeng, Z.; Zinner, M. J.; Zornig, C.; Jensen, M. A.; Sfeir, R.; Kahn, A. B.; Chu, A. L.; Kothiyal, P.; Wang, Z.; Snyder, E. E.; Pontius, J.; Pihl, T. D.; Ayala, B.; Backus, M.; Walton, J.; Whitmore, J.; Baboud, J.; Berton, D. L.; Nicholls, M. C.; Srinivasan, D.; Raman, R.; Girshik, S.; Kigonya, P. A.; Alonso, S.; Sanbhadti, R. N.; Barletta, S. P.; Greene, J. M.; Pot, D. A.; Shaw, K. R. M.; Dillon, L. A. L.; Buetow, K.; Davidsen, T.; Demchok, J. A.; Eley, G.; Ferguson, M.; Fielding, P.; Schaefer, C.; Sheth, M.; Yang, L.; Guyer, M. S.; Ozenberger, B. A.; Palchik, J. D.; Peterson, J.; Sofia, H. J.; Thomson., E. Comprehensive Molecular Characterization of Human Colon and Rectal Cancer.

Nature 2012 487:7407 2012, 487 (7407), 330-337.

https://doi.org/10.1038/nature11252.

(7) Yeo, S. K.; Guan, J. L. Breast Cancer: Multiple Subtypes within a Tumor? Trends in Cancer 2017, 3 (11), 753-760. https://doi.org/10.1016/j.trecan.2017.09.001.

(8) Yeo, S. K.; Zhu, X.; Okamoto, T.; Hao, M.; Wang, C.; Lu, P.; Lu, L. J.; Guan, J. L. SingleCell RNA-Sequencing Reveals Distinct Patterns of Cell State Heterogeneity in Mouse Models of Breast Cancer. eLife 2020, 9, 1-24. https://doi.org/10.7554/ELIFE.58810.

(9) Juiz, N.; Elkaoutari, A.; Bigonnet, M.; Gayet, O.; Roques, J.; Nicolle, R.; Iovanna, J.; Dusetti, N. Basal-like and Classical Cells Coexist in Pancreatic Cancer Revealed by Single-Cell Analysis on Biopsy-Derived Pancreatic Cancer Organoids from the Classical Subtype. The FASEB Journal 2020, 34 (9), 12214-12228.

https://doi.org/10.1096/FJ.202000363RR.

(10) Gallaher, J. A.; Enriquez-Navas, P. M.; Luddy, K. A.; Gatenby, R. A.; Anderson, A. R. A. Spatial Heterogeneity and Evolutionary Dynamics Modulate Time to Recurrence in Continuous and Adaptive Cancer Therapies. Cancer Research 2018, 78 (8), 21272139. https://doi.org/10.1158/0008-5472.CAN-17-2649.

(11) Suda, K.; Murakami, I.; Obata, K.; Sakai, K.; Fujino, T.; Koga, T.; Ohara, S.; Hamada, A.; Soh, J.; Nishio, K.; Mitsudomi, T. Spatial Heterogeneity of Acquired Resistance Mechanisms to 1st/2nd Generation EGFR Tyrosine Kinase Inhibitors in Lung Cancer. Lung cancer (Amsterdam, Netherlands) 2020, 148, 100-104. https://doi.org/10.1016/J.LUNGCAN.2020.08.010.

(12) Berglund, E.; Maaskola, J.; Schultz, N.; Friedrich, S.; Marklund, M.; Bergenstråhle, J.; Tarish, F.; Tanoglidi, A.; Vickovic, S.; Larsson, L.; Salmén, F.; Ogris, C.; Wallenborg, K.; Lagergren, J.; Ståhl, P.; Sonnhammer, E.; Helleday, T.; Lundeberg, J. Spatial Maps of Prostate Cancer Transcriptomes Reveal an Unexplored Landscape of Heterogeneity. Nature communications 2018, 9 (1). https://doi.org/10.1038/S41467-018-04724-5.

(13) Davnall, F.; Yip, C. S. P.; Ljungqvist, G.; Selmi, M.; Ng, F.; Sanghera, B.; Ganeshan, B.; Miles, K. A.; Cook, G. J.; Goh, V. Assessment of Tumor Heterogeneity: An Emerging Imaging Tool for Clinical Practice? Insights into Imaging 2012, 3 (6), 573-589. https://doi.org/10.1007/s13244-012-0196-6.

(14) Choi, Y. P.; Shim, H. S.; Gao, M.-Q.; Kang, S.; Cho, N. H. Molecular Portraits of Intratumoral Heterogeneity in Human Ovarian Cancer. Cancer Letters 2011, 307 (1), 62-71. https://doi.org/10.1016/j.canlet.2011.03.018.

(15) Chowdhury, R.; Ganeshan, B.; Irshad, S.; Lawler, K.; Eisenblätter, M.; Milewicz, H.; Rodriguez-Justo, M.; Miles, K.; Ellis, P.; Groves, A.; Punwani, S.; Ng, T. The Use of Molecular Imaging Combined with Genomic Techniques to Understand the Heterogeneity in Cancer Metastasis. The British Journal of Radiology 2014, 87 (1038), 20140065. https://doi.org/10.1259/bjr.20140065. 
(16) Caiado, F.; Silva-Santos, B.; Norell, H. Intra-Tumour Heterogeneity - Going beyond Genetics. The FEBS Journal 2016, 283 (12), 2245-2258.

https://doi.org/10.1111/febs.13705.

(17) Melo, F. D. S. E.; Vermeulen, L.; Fessler, E.; Medema, J. P. Cancer Heterogeneity-a Multifaceted View. EMBO reports 2013, 14 (8), 686-695.

https://doi.org/10.1038/embor.2013.92.

(18) Giraudeau, M.; Sepp, T.; Ujvari, B.; Renaud, F.; Tasiemski, A.; Roche, B.; Capp, J.-P.; Thomas, F. Differences in Mutational Processes and Intra-Tumour Heterogeneity between Organs. Evolution, Medicine, and Public Health 2019, 2019 (1), 139-146. https://doi.org/10.1093/emph/eoz017.

(19) Marusyk, A.; Almendro, V.; Polyak, K. Intra-Tumour Heterogeneity: A Looking Glass for Cancer? Nature Reviews Cancer 2012, 12 (5), 323-334. https://doi.org/10.1038/nrc3261.

(20) Alic, L.; Niessen, W. J.; Veenland, J. F. Quantification of Heterogeneity as a Biomarker in Tumor Imaging: A Systematic Review. PLoS ONE 2014, 9 (10), e110300. https://doi.org/10.1371/journal.pone.0110300.

(21) Just, N. Improving Tumour Heterogeneity MRI Assessment with Histograms. British Journal of Cancer 2014, 111 (12), 2205-2213. https://doi.org/10.1038/bjc.2014.512.

(22) Emblem, K. E.; Nedregaard, B.; Nome, T.; Due-Tonnessen, P.; Hald, J. K.; Scheie, D.; Borota, O. C.; Cvancarova, M.; Bjornerud, A. Glioma Grading by Using Histogram Analysis of Blood Volume Heterogeneity from MR-Derived Cerebral Blood Volume Maps. Radiology 2008, 247 (3), 808-817. https://doi.org/10.1148/radiol.2473070571.

(23) Ma, J. H.; Kim, H. S.; Rim, N.-J.; Kim, S.-H.; Cho, K.-G. Differentiation among Glioblastoma Multiforme, Solitary Metastatic Tumor, and Lymphoma Using WholeTumor Histogram Analysis of the Normalized Cerebral Blood Volume in Enhancing and Perienhancing Lesions. American Journal of Neuroradiology 2010, 31 (9), 16991706. https://doi.org/10.3174/ajnr.A2161.

(24) Peng, S.-L.; Chen, C.-F.; Liu, H.-L.; Lui, C.-C.; Huang, Y.-J.; Lee, T.-H.; Chang, C.-C.; Wang, F.-N. Analysis of Parametric Histogram from Dynamic Contrast-Enhanced MRI: Application in Evaluating Brain Tumor Response to Radiotherapy. NMR in Biomedicine 2013, 26 (4), 443-450. https://doi.org/10.1002/nbm.2882.

(25) Eccles, S. A.; Welch, D. R. Metastasis: Recent Discoveries and Novel Treatment Strategies. The Lancet 2007, 369 (9574), 1742-1757. https://doi.org/10.1016/S01406736(07)60781-8.

(26) Liu, D.; Chen, J.; Hu, X.; Yang, K.; Liu, Y.; Hu, G.; Ge, H.; Zhang, W.; Liu, H. ImagingGenomics in Glioblastoma: Combining Molecular and Imaging Signatures. Frontiers in Oncology 2021, 11, 2666. https://doi.org/10.3389/FONC.2021.699265/BIBTEX.

(27) Huang, Y.-L.; Chen, J.-H.; Shen, W.-C. Diagnosis of Hepatic Tumors With Texture Analysis in Nonenhanced Computed Tomography Images. Academic Radiology 2006, 13 (6), 713-720. https://doi.org/10.1016/j.acra.2005.07.014.

(28) Ng, F.; Kozarski, R.; Ganeshan, B.; Goh, V. Assessment of Tumor Heterogeneity by CT Texture Analysis: Can the Largest Cross-Sectional Area Be Used as an Alternative to Whole Tumor Analysis? European Journal of Radiology 2013, 82 (2), 342-348. https://doi.org/10.1016/j.ejrad.2012.10.023.

(29) Ganeshan, B.; Miles, K. A. Quantifying Tumour Heterogeneity with CT. Cancer Imaging 2013, 13 (1), 140-149. https://doi.org/10.1102/1470-7330.2013.0015. 
(30) Ganeshan, B.; Goh, V.; Mandeville, H. C.; Ng, Q. S.; Hoskin, P. J.; Miles, K. A. NonSmall Cell Lung Cancer: Histopathologic Correlates for Texture Parameters at CT. Radiology 2013, 266 (1), 326-336. https://doi.org/10.1148/radiol.12112428.

(31) Raman, S. P.; Chen, Y.; Schroeder, J. L.; Huang, P.; Fishman, E. K. CT Texture Analysis of Renal Masses. Academic Radiology 2014, 21 (12), 1587-1596.

https://doi.org/10.1016/j.acra.2014.07.023.

(32) Holli, K.; Lääperi, A.-L.; Harrison, L.; Luukkaala, T.; Toivonen, T.; Ryymin, P.; Dastidar, P.; Soimakallio, S.; Eskola, H. Characterization of Breast Cancer Types by Texture Analysis of Magnetic Resonance Images. Academic Radiology 2010, 17 (2), 135-141. https://doi.org/10.1016/j.acra.2009.08.012.

(33) Miles, K. A.; Ganeshan, B.; Griffiths, M. R.; Young, R. C. D.; Chatwin, C. R. Colorectal Cancer: Texture Analysis of Portal Phase Hepatic CT Images as a Potential Marker of Survival. Radiology 2009, 250 (2), 444-452.

https://doi.org/10.1148/radiol.2502071879.

(34) Ganeshan, B.; Panayiotou, E.; Burnand, K.; Dizdarevic, S.; Miles, K. Tumour Heterogeneity in Non-Small Cell Lung Carcinoma Assessed by CT Texture Analysis: A Potential Marker of Survival. European Radiology 2012, 22 (4), 796-802.

https://doi.org/10.1007/s00330-011-2319-8.

(35) Harrison, L. C.; Luukkaala, T.; Pertovaara, H.; Saarinen, T. O.; Heinonen, T. T.; Järvenpää, R.; Soimakallio, S.; Kellokumpu-Lehtinen, P.-L. I.; Eskola, H. J.; Dastidar, P. Non-Hodgkin Lymphoma Response Evaluation with MRI Texture Classification. Journal of Experimental \& Clinical Cancer Research 2009, 28 (1), 87. https://doi.org/10.1186/1756-9966-28-87.

(36) Waugh, S. A.; Purdie, C. A.; Jordan, L. B.; Vinnicombe, S.; Lerski, R. A.; Martin, P.; Thompson, A. M. Magnetic Resonance Imaging Texture Analysis Classification of Primary Breast Cancer. European Radiology 2016, 26 (2), 322-330. https://doi.org/10.1007/s00330-015-3845-6.

(37) Alic, L.; van Vliet, M.; van Dijke, C. F.; Eggermont, A. M. M.; Veenland, J. F.; Niessen, W. J. Heterogeneity in DCE-MRI Parametric Maps: A Biomarker for Treatment Response? Physics in Medicine and Biology 2011, 56 (6), 1601-1616. https://doi.org/10.1088/0031-9155/56/6/006.

(38) Harrison, L. C.; Luukkaala, T.; Pertovaara, H.; Saarinen, T. O.; Heinonen, T. T.; Järvenpää, R.; Soimakallio, S.; Kellokumpu-Lehtinen, P.-L. I.; Eskola, H. J.; Dastidar, P. Non-Hodgkin Lymphoma Response Evaluation with MRI Texture Classification. Journal of Experimental \& Clinical Cancer Research 2009, 28 (1), 87. https://doi.org/10.1186/1756-9966-28-87.

(39) Eary, J. F.; O’Sullivan, F.; O'Sullivan, J.; Conrad, E. U. Spatial Heterogeneity in Sarcoma ${ }^{18}$ F-FDG Uptake as a Predictor of Patient Outcome. Journal of Nuclear Medicine 2008, 49 (12), 1973-1979. https://doi.org/10.2967/jnumed.108.053397.

(40) Deleu, A.-L.; Sathekge, M. J.; Maes, A.; de Spiegeleer, B.; Sathekge, M.; van de Wiele, C. Characterization of FDG PET Images Using Texture Analysis in Tumors of the Gastro-Intestinal Tract: A Review. Biomedicines 2020, 8 (9), 304. https://doi.org/10.3390/biomedicines8090304.

(41) Hatt, M.; Tixier, F.; Pierce, L.; Kinahan, P. E.; le Rest, C. C.; Visvikis, D. Characterization of PET/CT Images Using Texture Analysis: The Past, the Present... Any Future? European Journal of Nuclear Medicine and Molecular Imaging 2017, 44 (1), 151-165. https://doi.org/10.1007/s00259-016-3427-0. 
(42) O'Sullivan, F. Incorporation of Tumor Shape into an Assessment of Spatial Heterogeneity for Human Sarcomas Imaged with FDG-PET. Biostatistics 2005, 6 (2), 293-301. https://doi.org/10.1093/biostatistics/kxi010.

(43) Huan Yu; Caldwell, C.; Mah, K.; Mozeg, D. Coregistered FDG PET/CT-Based Textural Characterization of Head and Neck Cancer for Radiation Treatment Planning. IEEE Transactions on Medical Imaging 2009, 28 (3), 374-383. https://doi.org/10.1109/TMI.2008.2004425.

(44) Vallières, M.; Freeman, C. R.; Skamene, S. R.; el Naqa, I. A Radiomics Model from Joint FDG-PET and MRI Texture Features for the Prediction of Lung Metastases in SoftTissue Sarcomas of the Extremities. Physics in Medicine and Biology 2015, 60 (14), 5471-5496. https://doi.org/10.1088/0031-9155/60/14/5471.

(45) Antunes, J.; Viswanath, S.; Rusu, M.; Valls, L.; Hoimes, C.; Avril, N.; Madabhushi, A. Radiomics Analysis on FLT-PET/MRI for Characterization of Early Treatment Response in Renal Cell Carcinoma: A Proof-of-Concept Study. Translational Oncology 2016, 9 (2), 155-162. https://doi.org/10.1016/j.tranon.2016.01.008.

(46) Kuikka, J. T. Fractal Analysis in Medical Imaging. International Journal of Nonlinear Sciences and Numerical Simulation 2002, 3 (2). https://doi.org/10.1515/IJNSNS.2002.3.2.81.

(47) Chen, C.-C.; DaPonte, J. S.; Fox, M. D. Fractal Feature Analysis and Classification in Medical Imaging. IEEE Transactions on Medical Imaging 1989, 8 (2), 133-142. https://doi.org/10.1109/42.24861.

(48) Kido, S.; Kuriyama, K.; Higashiyama, M.; Kasugai, T.; Kuroda, C. Fractal Analysis of Internal and Peripheral Textures of Small Peripheral Bronchogenic Carcinomas in Thin-Section Computed Tomography: Comparison of Bronchioloalveolar Cell Carcinomas With Nonbronchioloalveolar Cell Carcinomas. Journal of Computer Assisted Tomography 2003, 27 (1), 56-61. https://doi.org/10.1097/00004728200301000-00011.

(49) Goh, V.; Sanghera, B.; Wellsted, D. M.; Sundin, J.; Halligan, S. Assessment of the Spatial Pattern of Colorectal Tumour Perfusion Estimated at Perfusion CT Using TwoDimensional Fractal Analysis. European Radiology 2009, 19 (6), 1358-1365. https://doi.org/10.1007/s00330-009-1304-y.

(50) Sanghera, B.; Banerjee, D.; Khan, A.; Simcock, I.; Stirling, J. J.; Glynne-Jones, R.; Goh, V. Reproducibility of 2D and 3D Fractal Analysis Techniques for the Assessment of Spatial Heterogeneity of Regional Blood Flow in Rectal Cancer. Radiology 2012, 263 (3), 865-873. https://doi.org/10.1148/radiol.12111316.

(51) di leva, A.; Matula, C.; Grizzi, F.; Grabner, G.; Trattnig, S.; Tschabitscher, M. Fractal Analysis of the Susceptibility Weighted Imaging Patterns in Malignant Brain Tumors During Antiangiogenic Treatment: Technical Report on Four Cases Serially Imaged by 7 T Magnetic Resonance During a Period of Four Weeks. World Neurosurgery 2012, 77 (5-6), 785.e11-785.e21. https://doi.org/10.1016/j.wneu.2011.09.006.

(52) Rose, C. J.; Mills, S. J.; O'Connor, J. P. B.; Buonaccorsi, G. A.; Roberts, C.; Watson, Y.; Cheung, S.; Zhao, S.; Whitcher, B.; Jackson, A.; Parker, G. J. M. Quantifying Spatial Heterogeneity in Dynamic Contrast-Enhanced MRI Parameter Maps. Magnetic Resonance in Medicine 2009, 62 (2), 488-499. https://doi.org/10.1002/mrm.22003.

(53) Machireddy, A.; Thibault, G.; Tudorica, A.; Afzal, A.; Mishal, M.; Kemmer, K.; Naik, A.; Troxell, M.; Goranson, E.; Oh, K.; Roy, N.; Jafarian, N.; Holtorf, M.; Huang, W.; Song, X. Early Prediction of Breast Cancer Therapy Response Using Multiresolution Fractal 
Analysis of DCE-MRI Parametric Maps. Tomography 2019, 5 (1), 90-98. https://doi.org/10.18383/j.tom.2018.00046.

(54) Cebulla, J.; Kim, E.; Rhie, K.; Zhang, J.; Pathak, A. P. Multiscale and Multi-Modality Visualization of Angiogenesis in a Human Breast Cancer Model. Angiogenesis 2014, 17 (3), 695-709. https://doi.org/10.1007/s10456-014-9429-2.

(55) Walter, T.; Shattuck, D. W.; Baldock, R.; Bastin, M. E.; Carpenter, A. E.; Duce, S.; Ellenberg, J.; Fraser, A.; Hamilton, N.; Pieper, S.; Ragan, M. A.; Schneider, J. E.; Tomancak, P.; Hériché, J.-K. Visualization of Image Data from Cells to Organisms. Nature Methods 2010, 7 (S3), S26-S41. https://doi.org/10.1038/nmeth.1431.

(56) O'Connor, J. P. B.; Carano, R. A. D.; Clamp, A. R.; Ross, J.; Ho, C. C. K.; Jackson, A.; Parker, G. J. M.; Rose, C. J.; Peale, F. v.; Friesenhahn, M.; Mitchell, C. L.; Watson, Y.; Roberts, C.; Hope, L.; Cheung, S.; Reslan, H. B.; Go, M. A. T.; Pacheco, G. J.; Wu, X.; Cao, T. C.; Ross, S.; Buonaccorsi, G. A.; Davies, K.; Hasan, J.; Thornton, P.; del Puerto, O.; Ferrara, N.; van Bruggen, N.; Jayson, G. C. Quantifying Antivascular Effects of Monoclonal Antibodies to Vascular Endothelial Growth Factor: Insights from Imaging. Clinical Cancer Research 2009, 15 (21), 6674-6682. https://doi.org/10.1158/10780432.CCR-09-0731.

(57) Messiou, C.; Orton, M.; Ang, J. E.; Collins, D. J.; Morgan, V. A.; Mears, D.; Castellano, I.; Papadatos-Pastos, D.; Brunetto, A.; Tunariu, N.; Mann, H.; Tessier, J.; Young, H.; Ghiorghiu, D.; Marley, S.; Kaye, S. B.; deBono, J. S.; Leach, M. O.; deSouza, N. M. Advanced Solid Tumors Treated with Cediranib: Comparison of Dynamic ContrastEnhanced MR Imaging and CT as Markers of Vascular Activity. Radiology 2012, 265 (2), 426-436. https://doi.org/10.1148/radiol.12112565.

(58) Jackson, A.; O'Connor, J. P. B.; Parker, G. J. M.; Jayson, G. C. Imaging Tumor Vascular Heterogeneity and Angiogenesis Using Dynamic Contrast-Enhanced Magnetic Resonance Imaging. Clinical Cancer Research 2007, 13 (12), 3449-3459. https://doi.org/10.1158/1078-0432.CCR-07-0238.

(59) Berry, L. R.; Barck, K. H.; Go, M. A.; Ross, J.; Wu, X.; Williams, S. P.; Gogineni, A.; Cole, M. J.; van Bruggen, N.; Fuh, G.; Peale, F.; Ferrara, N.; Ross, S.; Schwall, R. H.; Carano, R. A. D. Quantification of Viable Tumor Microvascular Characteristics by Multispectral Analysis. Magnetic Resonance in Medicine 2008, 60 (1), 64-72.

https://doi.org/10.1002/mrm.21470.

(60) Heaster, T. M.; Landman, B. A.; Skala, M. C. Quantitative Spatial Analysis of Metabolic Heterogeneity Across in Vivo and in Vitro Tumor Models. Frontiers in Oncology 2019, 9, 1144. https://doi.org/10.3389/FONC.2019.01144/BIBTEX.

(61) Carmona-Fontaine, C.; Deforet, M.; Akkari, L.; Thompson, C. B.; Joyce, J. A.; Xavier, J. B. Metabolic Origins of Spatial Organization in the Tumor Microenvironment. Proceedings of the National Academy of Sciences of the United States of America 2017, 114 (11), 2934-2939. https://doi.org/10.1073/PNAS.1700600114.

(62) Serganova, I.; Doubrovin, M.; Vider, J.; Ponomarev, V.; Soghomonyan, S.; Beresten, T.; Ageyeva, L.; Serganov, A.; Cai, S.; Balatoni, J.; Blasberg, R.; Gelovani, J. Molecular Imaging of Temporal Dynamics and Spatial Heterogeneity of Hypoxia-Inducible Factor-1 Signal Transduction Activity in Tumors in Living Mice. Cancer research 2004, 64 (17), 6101-6108. https://doi.org/10.1158/0008-5472.CAN-04-0842.

(63) Saxena, K.; Jolly, M. K. Acute vs. Chronic vs. Cyclic Hypoxia: Their Differential Dynamics, Molecular Mechanisms, and Effects on Tumor Progression. Biomolecules. 2019. https://doi.org/10.3390/biom9080339. 
(64) Walsh, A. J.; Skala, M. C. Optical Metabolic Imaging Quantifies Heterogeneous Cell Populations. Biomedical Optics Express 2015, 6 (2), 559.

https://doi.org/10.1364/BOE.6.000559.

(65) de Back, W.; Zerjatke, T.; Roeder, I. Statistical and Mathematical Modeling of Spatiotemporal Dynamics of Stem Cells; 2019; pp 219-243.

https://doi.org/10.1007/978-1-4939-9574-5_17.

(66) Heaster, T. M.; Landman, B. A.; Skala, M. C. Quantitative Spatial Analysis of Metabolic Heterogeneity Across in Vivo and in Vitro Tumor Models. Frontiers in Oncology 2019, 9. https://doi.org/10.3389/fonc.2019.01144.

(67) Walsh, A. J.; Cook, R. S.; Manning, H. C.; Hicks, D. J.; Lafontant, A.; Arteaga, C. L.; Skala, M. C. Optical Metabolic Imaging Identifies Glycolytic Levels, Subtypes, and Early-Treatment Response in Breast Cancer. Cancer Research 2013, 73 (20), 61646174. https://doi.org/10.1158/0008-5472.CAN-13-0527.

(68) Georgakoudi, I.; Quinn, K. P. Optical Imaging Using Endogenous Contrast to Assess Metabolic State. Annual Review of Biomedical Engineering 2012, 14 (1), 351-367. https://doi.org/10.1146/annurev-bioeng-071811-150108.

(69) Sharick, J. T.; Favreau, P. F.; Gillette, A. A.; Sdao, S. M.; Merrins, M. J.; Skala, M. C. Protein-Bound NAD(P)H Lifetime Is Sensitive to Multiple Fates of Glucose Carbon. Scientific Reports 2018, 8 (1), 5456. https://doi.org/10.1038/s41598-018-23691-x.

(70) Liu, Z.; Pouli, D.; Alonzo, C. A.; Varone, A.; Karaliota, S.; Quinn, K. P.; Münger, K.; Karalis, K. P.; Georgakoudi, I. Mapping Metabolic Changes by Noninvasive, Multiparametric, High-Resolution Imaging Using Endogenous Contrast. Science Advances 2018, 4 (3). https://doi.org/10.1126/sciadv.aap9302.

(71) Garvalov, B. K.; Ertürk, A. Seeing Whole-Tumour Heterogeneity. Nature Biomedical Engineering 2017, 1 (10), 772-774. https://doi.org/10.1038/s41551-017-0150-5.

(72) Herzog, E.; Taruttis, A.; Beziere, N.; Lutich, A. A.; Razansky, D.; Ntziachristos, V. Optical Imaging of Cancer Heterogeneity with Multispectral Optoacoustic Tomography. Radiology 2012, 263 (2), 461-468. https://doi.org/10.1148/radiol.11111646.

(73) Li, J.; Chekkoury, A.; Prakash, J.; Glasl, S.; Vetschera, P.; Koberstein-Schwarz, B.; Olefir, I.; Gujrati, V.; Omar, M.; Ntziachristos, V. Spatial Heterogeneity of Oxygenation and Haemodynamics in Breast Cancer Resolved in Vivo by Conical Multispectral Optoacoustic Mesoscopy. Light: Science \& Applications 2020, 9 (1), 57. https://doi.org/10.1038/s41377-020-0295-y.

(74) Porta Siegel, T.; Hamm, G.; Bunch, J.; Cappell, J.; Fletcher, J. S.; Schwamborn, K. Mass Spectrometry Imaging and Integration with Other Imaging Modalities for Greater Molecular Understanding of Biological Tissues. Molecular Imaging and Biology 2018, 20 (6), 888-901. https://doi.org/10.1007/s11307-018-1267-y.

(75) Morjaria, S.; Morjaria, S. Driver Mutations in Oncogenesis. International Journal of Molecular \& Immuno Oncology 2021, 6 (2), 100-102. https://doi.org/10.25259/IJMIO_26_2020.

(76) Liu, S.; Cong, Y.; Wang, D.; Sun, Y.; Deng, L.; Liu, Y.; Martin-Trevino, R.; Shang, L.; McDermott, S. P.; Landis, M. D.; Hong, S.; Adams, A.; D’Angelo, R.; Ginestier, C.; Charafe-Jauffret, E.; Clouthier, S. G.; Birnbaum, D.; Wong, S. T.; Zhan, M.; Chang, J. C.; Wicha, M. S. Breast Cancer Stem Cells Transition between Epithelial and Mesenchymal States Reflective of Their Normal Counterparts. Stem cell reports 2013, 2 (1), 78-91. https://doi.org/10.1016/J.STEMCR.2013.11.009. 
(77) Brabletz, T.; Jung, A.; Reu, S.; Porzner, M.; Hlubek, F.; Kunz-Schughart, L. A.; Knuechel, R.; Kirchner, T. Variable $\beta$-Catenin Expression in Colorectal Cancers Indicates Tumor Progression Driven by the Tumor Environment. Proceedings of the National Academy of Sciences 2001, 98 (18), 10356-10361. https://doi.org/10.1073/PNAS.171610498.

(78) Sun, H.; Zhang, D.; Huang, C.; Guo, Y.; Yang, Z.; Yao, N.; Dong, X.; Cheng, R.; Zhao, N.; Meng, J.; Sun, B.; Hao, J. Hypoxic Microenvironment Induced Spatial Transcriptome Changes in Pancreatic Cancer. Cancer Biology and Medicine 2021, 18 (2), 616-630. https://doi.org/10.20892/j.issn.2095-3941.2021.0158.

(79) Moncada, R.; Barkley, D.; Wagner, F.; Chiodin, M.; Devlin, J. C.; Baron, M.; Hajdu, C. H.; Simeone, D. M.; Yanai, I. Integrating Microarray-Based Spatial Transcriptomics and Single-Cell RNA-Seq Reveals Tissue Architecture in Pancreatic Ductal Adenocarcinomas. Nature biotechnology 2020, 38 (3), 333-342. https://doi.org/10.1038/S41587-019-0392-8.

(80) Aggarwal, R. R.; Quigley, D. A.; Huang, J.; Zhang, L.; Beer, T. M.; Rettig, M. B.; Reiter, R. E.; Gleave, M. E.; Thomas, G. V.; Foye, A.; Playdle, D.; Lloyd, P.; Chi, K. N.; Evans, C. P.; Lara, P. N.; Feng, F. Y.; Alumkal, J. J.; Small, E. J. Whole Genome and Transcriptional Analysis of Treatment-Emergent Small Cell Neuroendocrine Prostate Cancer Demonstrates Intra-Class Heterogeneity. Molecular cancer research : MCR 2019, 17 (6), 1235. https://doi.org/10.1158/1541-7786.MCR-18-1101.

(81) Chauhan, L.; Ram, U.; Hari, K.; Jolly, M. K. Topological Signatures in Regulatory Network Enable Phenotypic Heterogeneity in Small Cell Lung Cancer. eLife 2021, 10, e64522.

(82) Thankamony, A. P.; Subbalakshmi, A. R.; Jolly, M. K.; Nair, R. Lineage Plasticity in Cancer: The Tale of a Skin-Walker. Cancers 2021, 13 (14).

https://doi.org/10.3390/CANCERS13143602.

(83) Pachynski, R. K.; Kim, E. H.; Miheecheva, N.; Kotlov, N.; Ramachandran, A.; Postovalova, E.; Galkin, I.; Svekolkin, V.; Lyu, Y.; Zou, Q.; Cao, D.; Gaut, J.; Ippolito, J. E.; Bagaev, A.; Bruttan, M.; Gancharova, O.; Nomie, K.; Tsiper, M.; Andriole, G. L.; Ataullakhanov, R.; Hsieh, J. J. Single-Cell Spatial Proteomic Revelations on the Multiparametric MRI Heterogeneity of Clinically Significant Prostate Cancer. Clinical cancer research : an official journal of the American Association for Cancer Research 2021, 27 (12), 3478-3490. https://doi.org/10.1158/1078-0432.CCR-20-4217.

(84) Wang, Y.; Ma, S.; Ruzzo, W. L. Spatial Modeling of Prostate Cancer Metabolic Gene Expression Reveals Extensive Heterogeneity and Selective Vulnerabilities. Scientific reports 2020, 10 (1). https://doi.org/10.1038/S41598-020-60384-W.

(85) Merritt, C. R.; Ong, G. T.; Church, S. E.; Barker, K.; Danaher, P.; Geiss, G.; Hoang, M.; Jung, J.; Liang, Y.; McKay-Fleisch, J.; Nguyen, K.; Norgaard, Z.; Sorg, K.; Sprague, I.; Warren, C.; Warren, S.; Webster, P. J.; Zhou, Z.; Zollinger, D. R.; Dunaway, D. L.; Mills, G. B.; Beechem, J. M. Multiplex Digital Spatial Profiling of Proteins and RNA in Fixed Tissue. Nature Biotechnology 2020 38:5 2020, 38 (5), 586-599. https://doi.org/10.1038/s41587-020-0472-9.

(86) Beechem, J. M. High-Plex Spatially Resolved RNA and Protein Detection Using Digital Spatial Profiling: A Technology Designed for Immuno-Oncology Biomarker Discovery and Translational Research. Methods in Molecular Biology 2020, 2055, 563-583. https://doi.org/10.1007/978-1-4939-9773-2_25.

(87) Brady, L.; Kriner, M.; Coleman, I.; Morrissey, C.; Roudier, M.; True, L. D.; Gulati, R.; Plymate, S. R.; Zhou, Z.; Birditt, B.; Meredith, R.; Geiss, G.; Hoang, M.; Beechem, J.; 
Nelson, P. S. Inter- and Intra-Tumor Heterogeneity of Metastatic Prostate Cancer Determined by Digital Spatial Gene Expression Profiling. Nature communications 2021, 12 (1). https://doi.org/10.1038/S41467-021-21615-4.

(88) Chakraborty, P.; Chen, E. L.; McMullen, I.; Armstrong, A. J.; Kumar Jolly, M.; Somarelli, J. A. Analysis of Immune Subtypes across the Epithelial-Mesenchymal Plasticity Spectrum. Computational and Structural Biotechnology Journal 2021, 19, 3842-3851. https://doi.org/10.1016/j.csbj.2021.06.023.

(89) Abdalla, M.; Tran-Thanh, D.; Moreno, J.; lakovlev, V.; Nair, R.; Kanwar, N.; Abdalla, M.; Lee, J. P. Y.; Kwan, J. Y. Y.; Cawthorn, T. R.; Warren, K.; Arneson, N.; Wang, D. Y.; Fox, N. S.; Youngson, B. J.; Miller, N. A.; Easson, A. M.; McCready, D.; Leong, W. L.; Boutros, P. C.; Done, S. J. Mapping Genomic and Transcriptomic Alterations Spatially in Epithelial Cells Adjacent to Human Breast Carcinoma. Nature communications 2017, 8 (1). https://doi.org/10.1038/S41467-017-01357-Y.

(90) Nakayama, J.; Matsunaga, H.; Arikawa, K.; Yoda, T.; Hosokawa, M.; Takeyama, H.; Yamamoto, Y.; Semba, K. Spatial Transcriptomics Reveals the Two Cancer Stem Celllike Populations in Triple-Negative Breast Cancer. bioRxiv 2021, 2021.10.21.465257. https://doi.org/10.1101/2021.10.21.465257.

(91) Elosua-Bayes, M.; Nieto, P.; Mereu, E.; Gut, I.; Heyn, H. SPOTlight: Seeded NMF Regression to Deconvolute Spatial Transcriptomics Spots with Single-Cell Transcriptomes. Nucleic acids research 2021, 49 (9), E50. https://doi.org/10.1093/NAR/GKAB043.

(92) Edsgärd, D.; Johnsson, P.; Sandberg, R. Identification of Spatial Expression Trends in Single-Cell Gene Expression Data. Nature Methods 2018, 15 (5), 339-342. https://doi.org/10.1038/nmeth.4634.

(93) Joost, S.; Zeisel, A.; Jacob, T.; Sun, X.; la Manno, G.; Lönnerberg, P.; Linnarsson, S.; Kasper, M. Single-Cell Transcriptomics Reveals That Differentiation and Spatial Signatures Shape Epidermal and Hair Follicle Heterogeneity. Cell Systems 2016, 3 (3), 221-237.e9. https://doi.org/10.1016/J.CELS.2016.08.010.

(94) Sahoo, S.; Nayak, S. P.; Hari, K.; Mandal, S.; Kishore, A.; Levine, H.; Kumar Jolly, M. Immunosuppressive Traits of the Hybrid Epithelial/Mesenchymal Phenotype Running Title: Hybrid Epithelial/Mesenchymal Cells Have High PD-L1 Levels. https://doi.org/10.1101/2021.06.21.449285.

(95) Petropoulos, S.; Edsgärd, D.; Reinius, B.; Deng, Q.; Panula, S. P.; Codeluppi, S.; Plaza Reyes, A.; Linnarsson, S.; Sandberg, R.; Lanner, F. Single-Cell RNA-Seq Reveals Lineage and X Chromosome Dynamics in Human Preimplantation Embryos. Cell 2016, 165 (4), 1012. https://doi.org/10.1016/J.CELL.2016.03.023.

(96) Levy-Jurgenson, A.; Tekpli, X.; Kristensen, V. N.; Yakhini, Z. Spatial Transcriptomics Inferred from Pathology Whole-Slide Images Links Tumor Heterogeneity to Survival in Breast and Lung Cancer. Scientific Reports 2020, 10 (1). https://doi.org/10.1038/s41598-020-75708-z.

(97) He, B.; Bergenstråhle, L.; Stenbeck, L.; Abid, A.; Andersson, A.; Borg, Å.; Maaskola, J.; Lundeberg, J.; Zou, J. Integrating Spatial Gene Expression and Breast Tumour Morphology via Deep Learning. Nature Biomedical Engineering 2020, 4 (8), 827-834. https://doi.org/10.1038/s41551-020-0578-x.

(98) Chakraborty, P.; George, J. T.; Woodward, W. A.; Levine, H.; Jolly, M. K. Gene Expression Profiles of Inflammatory Breast Cancer Reveal High Heterogeneity across 
the Epithelial-Hybrid-Mesenchymal Spectrum. Translational oncology 2021, 14 (4). https://doi.org/10.1016/J.TRANON.2021.101026.

(99) Ahl, P. J.; Hopkins, R. A.; Xiang, W. W.; Au, B.; Kaliaperumal, N.; Fairhurst, A. M.; Connolly, J. E. Met-Flow, a Strategy for Single-Cell Metabolic Analysis Highlights Dynamic Changes in Immune Subpopulations. Communications Biology 2020 3:1 2020, 3 (1), 1-15. https://doi.org/10.1038/s42003-020-1027-9.

(100) Clark, S. J.; Lee, H. J.; Smallwood, S. A.; Kelsey, G.; Reik, W. Single-Cell Epigenomics: Powerful New Methods for Understanding Gene Regulation and Cell Identity. Genome Biology 2016, 17 (1), 1-10. https://doi.org/10.1186/S13059-016-0944$\mathrm{X} /$ FIGURES/2.

(101) Petelski, A. A.; Emmott, E.; Leduc, A.; Huffman, R. G.; Specht, H.; Perlman, D. H.; Slavov, N. Multiplexed Single-Cell Proteomics Using SCOPE2. Nature protocols 2021, 16 (12), 5398-5425. https://doi.org/10.1038/S41596-021-00616-Z.

(102) Lee, J. H.; Daugharthy, E. R.; Scheiman, J.; Kalhor, R.; Yang, J. L.; Ferrante, T. C.; Terry, R.; Jeanty, S. S. F.; Li, C.; Amamoto, R.; Peters, D. T.; Turczyk, B. M.; Marblestone, A. H.; Inverso, S. A.; Bernard, A.; Mali, P.; Rios, X.; Aach, J.; Church, G. M. Highly Multiplexed Subcellular RNA Sequencing in Situ. Science 2014, 343 (6177), 13601363. https://doi.org/10.1126/SCIENCE.1250212/SUPPL_FILE/LEE.SM.PDF.

(103) Savulescu, A. F.; Jacobs, C.; Negishi, Y.; Davignon, L.; Mhlanga, M. M. Pinpointing Cell Identity in Time and Space. Frontiers in Molecular Biosciences 2020, 7. https://doi.org/10.3389/fmolb.2020.00209.

(104) Wang, N.; Li, X.; Wang, R.; Ding, Z. Spatial Transcriptomics and Proteomics Technologies for Deconvoluting the Tumor Microenvironment. Biotechnology Journal 2021, 16 (9), 2100041. https://doi.org/10.1002/biot.202100041.

(105) Raj, A.; van den Bogaard, P.; Rifkin, S. A.; van Oudenaarden, A.; Tyagi, S. Imaging Individual MRNA Molecules Using Multiple Singly Labeled Probes. Nature methods 2008, 5 (10), 877-879. https://doi.org/10.1038/NMETH.1253.

(106) Bingham, G. C.; Lee, F.; Naba, A.; Barker, T. H. Spatial-Omics: Novel Approaches to Probe Cell Heterogeneity and Extracellular Matrix Biology. Matrix Biology 2020, 9192, 152-166. https://doi.org/10.1016/j.matbio.2020.04.004.

(107) Srivatsan, S. R.; Regier, M. C.; Barkan, E.; Franks, J. M.; Packer, J. S.; Grosjean, P.; Duran, M.; Saxton, S.; Ladd, J. J.; Spielmann, M.; Lois, C.; Lampe, P. D.; Shendure, J.; Stevens, K. R.; Trapnell, C. Embryo-Scale, Single-Cell Spatial Transcriptomics. Science 2021, 373 (6550), 111-117. https://doi.org/10.1126/science.abb9536.

(108) Zhu, Q.; Shah, S.; Dries, R.; Cai, L.; Yuan, G.-C. Identification of Spatially Associated Subpopulations by Combining ScRNAseq and Sequential Fluorescence in Situ Hybridization Data. Nature Biotechnology 2018, 36 (12), 1183-1190. https://doi.org/10.1038/nbt.4260.

(109) Tasic, B.; Menon, V.; Nguyen, T. N.; Kim, T. K.; Jarsky, T.; Yao, Z.; Levi, B.; Gray, L. T.; Sorensen, S. A.; Dolbeare, T.; Bertagnolli, D.; Goldy, J.; Shapovalova, N.; Parry, S.; Lee, C.; Smith, K.; Bernard, A.; Madisen, L.; Sunkin, S. M.; Hawrylycz, M.; Koch, C.; Zeng, H. Adult Mouse Cortical Cell Taxonomy Revealed by Single Cell Transcriptomics. Nature Neuroscience 2016, 19 (2), 335-346. https://doi.org/10.1038/nn.4216. 


\section{Figures}

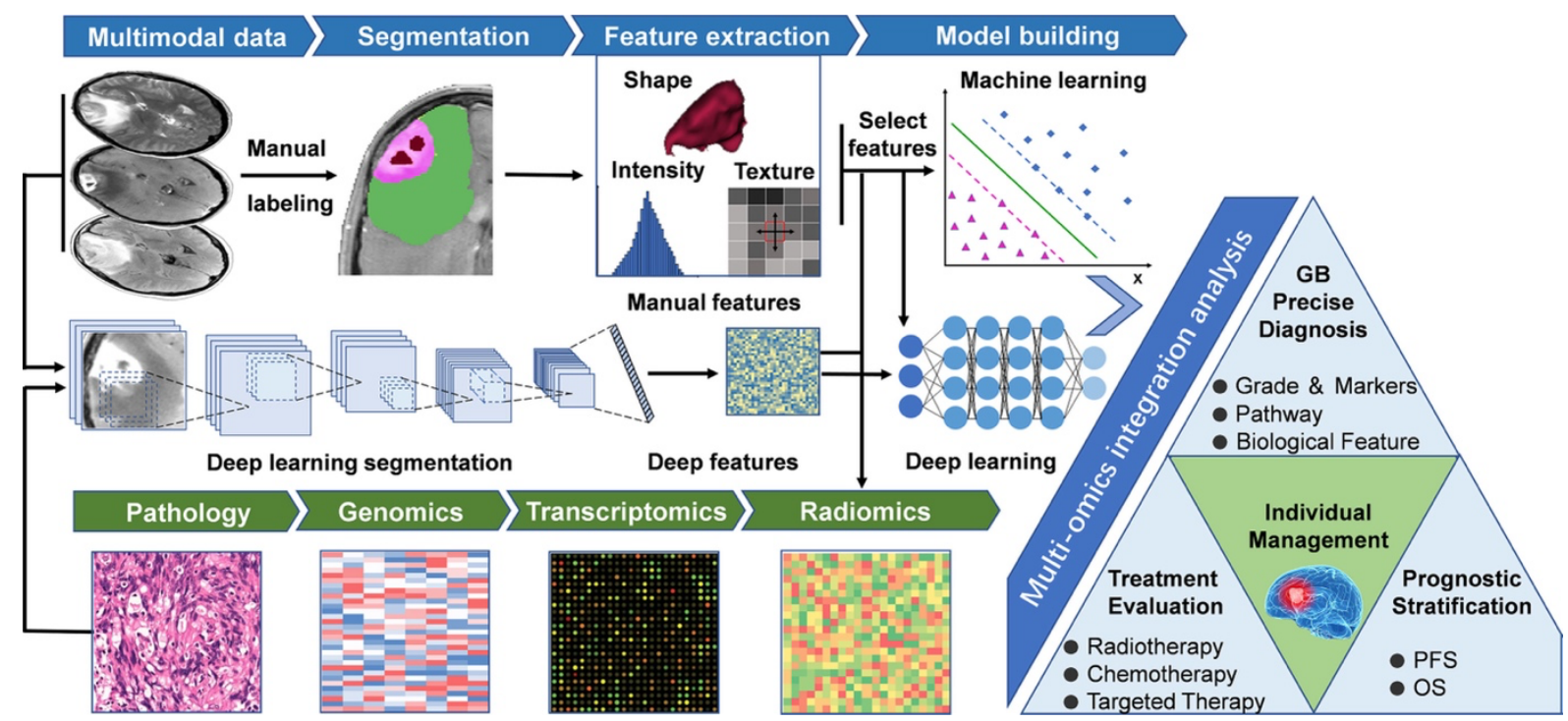

Fig 1: Neuro-oncology radiomics study workflow. 1) Multimodal imaging and biological data acquisition; (2) Data preprocessing and standardization; (3) Delineation of regions of interest, including manual segmentation and deep learning-based segmentation; (4) Radiomics feature extraction using predefined algorithms or deep learning techniques; (5) Data analysis, feature reduction, and/or selection for further analysis of machine learning and/or deep neural networks; (6) Multi-omics and clinical information integrated model training and testing, guiding individualized disease diagnosis, treatment evaluation, and prognosis prediction. GB, Glioblastoma; OS, Overall Survival; PFS, Progression free survival. (Figure and description adapted from Liu et al. 2021 (26)). 
a

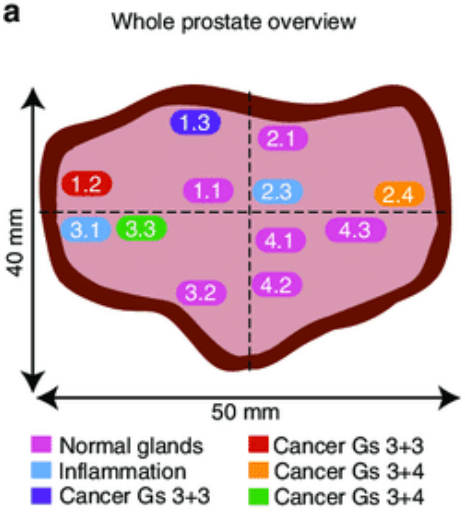

b

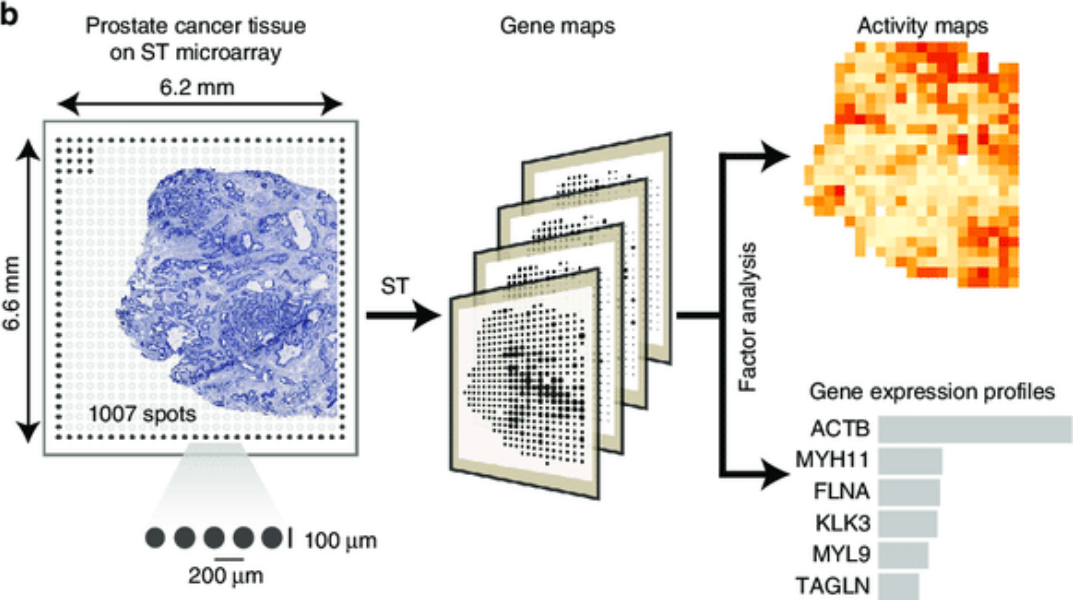

Fig 2: Spatial Transcriptomics (ST) study design in prostate cancer. a Sample location used in this study and annotations made by a pathologist. The sections annotations are colour coded. Prostate size is indicated by scale bar. b 1007 spatially barcoded spots of the spatial microarray. The barcoded spots have a diameter of $100 \mu \mathrm{m}$ and have a $200 \mu \mathrm{m}$ center-to-center distance.Orientation, and lack spatial barcodes are denoted by filled circles. The ST procedure yields matrices with read counts for every gene in every spot, which are then decomposed by factor analysis resulting in a set of factors ("cell types"), each comprising one activity map and one expression profile. (Figure and description adapted from Berglund et al. 2018 (12)) 